\title{
Reference values for the 6-minute walk test in healthy children and adolescents in Switzerland
}

\author{
Silvia Ulrich ${ }^{1,8^{*}+}$, Florian F Hildenbrand ${ }^{2 \dagger}$, Ursula Treder ${ }^{3}$, Manuel Fischler ${ }^{4}$, Stephan Keusch ${ }^{5}$, Rudolf Speich \\ and Margrit Fasnacht ${ }^{7}$
}

\begin{abstract}
Background: The six-minute walk test (6MWT) is a simple, low tech, safe and well established, self-paced assessment tool to quantify functional exercise capacity in adults. The definition of normal 6MWT in children is especially demanding since not only parameters like height, weight and ethnical background influence the measurement, but may be as crucial as age and the developmental stage. The aim of this study is establishing reference values for the 6MWT in healthy children and adolescents in Switzerland and to investigate the influence of age, anthropometrics, heart rate, blood pressure and physical activity on the distance walked.

Methods: Children and adolescents between 5-17 years performed a 6MWT. Short questionnaire assessments about their health state and physical activities. anthropometrics and vitals were measured before and after a 6-minute walk test and were previously defined as secondary outcomes.

Results: Age, height, weight and the heart rate after the 6MWT all predicted the distance walked according to different regression models: age was the best single predictor and mostly influenced walk distance in younger age, anthropometrics were more important in adolescents and females. Heart rate after the 6MWT was an important distance predictor in addition to age and outreached anthropometrics in the majority of subgroups assessed.

Conclusions: The 6MWT in children and adolescents is feasible and practical. The 6MWT distance depends mainly on age; however, heart rate after the 6MWT, height and weight significantly add information and should be taken into account mainly in adolescents. Reference equations allow predicting 6-minute walk test distance and may help to better assess and compare outcomes in young patients with cardiovascular and respiratory diseases and are highly warranted for different populations.
\end{abstract}

Keywords: 6-minute walk test, Healthy children, Exercise physiology, Exercise testing, Predicted equation, Reference value

\section{Background}

The six-minute walk test (6MWT) is a simple, low tech, safe and well established self-paced assessment tool to quantify functional exercise capacity in individual with various cardiorespiratory diseases [1]. The $6 \mathrm{MWT}$ is performed by instructing the participant to walk as fast as possible (without running) on a flat surface in $6 \mathrm{mi}-$ nutes, the distance walked (6MWD) is recorded [1]. The

\footnotetext{
*Correspondence: silvia.ulrich@usz.ch

${ }^{\dagger}$ Equal contributors

'Department of Heart, Vessel, Thorax, University Hospital of Zurich,

Switzerland and Centre of Integrative Human Physiology, Zurich, Switzerland

${ }^{8}$ Respiratory Clinic, University Hospital of Zurich, Rämistrasse 100, 8091

Zürich, Switzerland

Full list of author information is available at the end of the article
}

6MWD is a good predictor for morbidity and mortality in various diseases in adult populations [2-6]. Normal values available for the 6MWD are based on different adult cohorts [7-9]. From these, patients' 6MWD in \% predicted of normal values can be calculated by formulas. However, whether the expression of 6MWD in \% predicted provide better prognostic information is still debated [9].

The definition of normal 6MWD in children is especially demanding since not only parameters like height, weight and ethnical background influence the measurement, but may be as crucial as age and the developmental stage [10]. Therefore a reliable comparison with healthy children of similar age, ethnical background and

\section{Biomed Central}


posture is important. Values for children living in different countries may not directly applicable to each other [5]. Until now, data on normal values of the 6MWD performed according to ATS standards for healthy children and adolescence of both sex living in Central Europe are very rare and highly warranted in order to have comparative data for children and adolescents with disease. Previous studies assessing normal values for the 6MWD in children or adolescent mostly investigated restricted age ranges, distinct ethnics, were limited by their small number of participants or investigated modified 6MWD tests [10-12].

The aim of the present study was to provide reference values of the 6MWD based on demographics for children and adolescents, aged 5-17 years living in Switzerland. Further aims were to study the differential influence of age, sex, height and weight on the 6MWD and the potential added values of arterial blood pressure (BP), heart rate (HR) before and after the 6MWD and questionnaire-assessed physical activity in everyday life. We aimed to study the above-mentioned measures taken as a whole, gender-specific and separately for children and adolescents as we hypothesised that age, sex and anthropometrics would influence the distance walked.

\section{Methods}

\section{Patients}

This study was performed according to the Declaration of Helsinki, ICH-GCP as well as all national legal and regulatory requirements. The study was approved by the local ethics committee (Ethics committee University of Zurich). The authors of this manuscript comply with the Principles of Ethical Publishing in the International Journal of Cardiology [13]. Written informed consent for all participants was given by parents or legal guardian as well as by subjects. Recruitment took place at Swiss schools in rural and urban areas after contacting the authorities by an information letter and through mouthto-mouth propaganda. All candidates asked to participate took part in this study. Questionnaire assessment and $6 \mathrm{MWT}$ were performed by the same two study nurses in all participants.

\section{6 minute walk test}

Questionnaire and 6MWT took place at the same day. In brief, exact age and sex were noted. Body weight and height were measured and the body mass index (BMI, in $\mathrm{kg} / \mathrm{m}^{2}$ ) was calculated by dividing the weight (in $\mathrm{kg}$ ) by the square of the body height in meters $(\mathrm{m})$. Thereafter, the blood pressure $(\mathrm{mmHg})$, heart rate $(\mathrm{bpm})$ and the peripheral arterial oxygen saturation $\left(\mathrm{SpO}_{2} \%\right)$ were measured after a resting period in sitting position for at least 5 minutes. Thereafter the $6 \mathrm{MWT}$ was performed according to the guidelines of the American Thoracic
Society for adults [1]. Children and adolescents were instructed according to a standardised protocol to perform the 6MWT by walking around two flagpoles positioned $30 \mathrm{~m}$ apart on a flat ground. Subjects were instructed to walk as fast as possible (without running) at a steady pace for 6 minutes. After 5 minutes time left had been advised to the participant. No other commandos or verbal feedback was given. Specially trained study nurses who supervised the test measured the exact covered distance. Directly after the test, exercise BP, HR and $\mathrm{SpO}_{2}$ were re-measured. The mean arterial pressure (MAP) was calculated by adding twice the diastolic pressure to the systolic pressure and dividing the sum by three.

\section{Questionnaire assessments}

Health state of participants was assessed by a standardised questionnaire asking the following information from parents and adolescents, respectively: Is your child/ are you healthy? Is your child/are you able to participate normally in physical activities? Is your child/are you taking regular medication? Does your child/do you suffer from asthma or another chronic disease? Did your child/ did you have an operation of the lower extremities, which make it difficult for you to walk? If with the aid of this questionnaire disability was detected, the child was excluded from the study. In addition, we asked for physical activities as follows: How many hours do your child/ do you participate in physical activities a week beside the obligatory school sport? Answers were scored referred to physical activity score (PAS) on a scale between 0 and 4 with 0 standing for no additional physical

\section{Table 1 Patients' characteristics I}

\begin{tabular}{cc}
\hline & $\begin{array}{c}\text { Numbers (\%) } \\
\text { Mean } \pm \text { SD }\end{array}$ \\
\hline Total number of patients & 496 \\
Female/male & 252/244 (51/49) \\
Body weight (kg) & $11.1 \pm 3.4$ \\
Height (cm) & $41 \pm 17$ \\
Body mass index (kg/m ${ }^{2}$ ) & $147 \pm 2$ \\
Mean Artery Pressure before test (mmHg) & $17.9 \pm 3.3$ \\
Mean Artery Pressure after test (mmHg) & $80 \pm 10$ \\
Pulse rate before test (bpm) & $87 \pm 11$ \\
Pulse rate after test (bpm) & $95 \pm 16$ \\
Pulse rate increase (bpm) & $136 \pm 23$ \\
Transcutaneous oxygen saturation before test (\%) & $41 \pm 23$ \\
Transcutaneous oxygen saturation after test (\%) & $97 \pm 4$ \\
Desaturation (\%) & $97 \pm 1$ \\
Six-minute walking distance (m) & $0 \pm 1$
\end{tabular}


activity, 1 for $1-2,2$ for $3-4$ and 4 for $>4$ hours of weekly physical activity.

\section{Statistical methods and power calculation}

Power calculation on the basis of the available data from adults [7] revealed that with the assumption of a standard deviation of $40 \mathrm{~m}$ per age group the inclusion of 20 girls and boys each for each age year resulting in testing a total of 440 children respectively adolescents would be sufficient to provide reliable normal values of the 6MWD for the age groups tested including an alpha error of 5\%. Characteristics of the participants are summarized by means \pm (standard deviation, SD). Patients were allocated into yearly age groups and binary by an assumed onset of puberty at 12 years in girls and 13 years in boys in children and adolescents. Baseline variables for different groups have been compared using Mann-Whitney- $U$-Test. Percentile curves were plotted using a specialized computer program (LMSchartmaker pro, Version 2.43, http:// homepage.mac.com/tjcole). Pearson correlation, linear and step-wise multiple linear regressions as provided by the SPSS program were used to correlate characteristics with the 6MWD and to provide prediction equations for the 6MWD. Durbin-Watson tests (DW) were used to correct for autocorrelation in multiple linear regression models. IBM, SPSS package Version 21 was used for statistical calculation. A probability of $\mathrm{P}<0.05$ has to be considered significant.

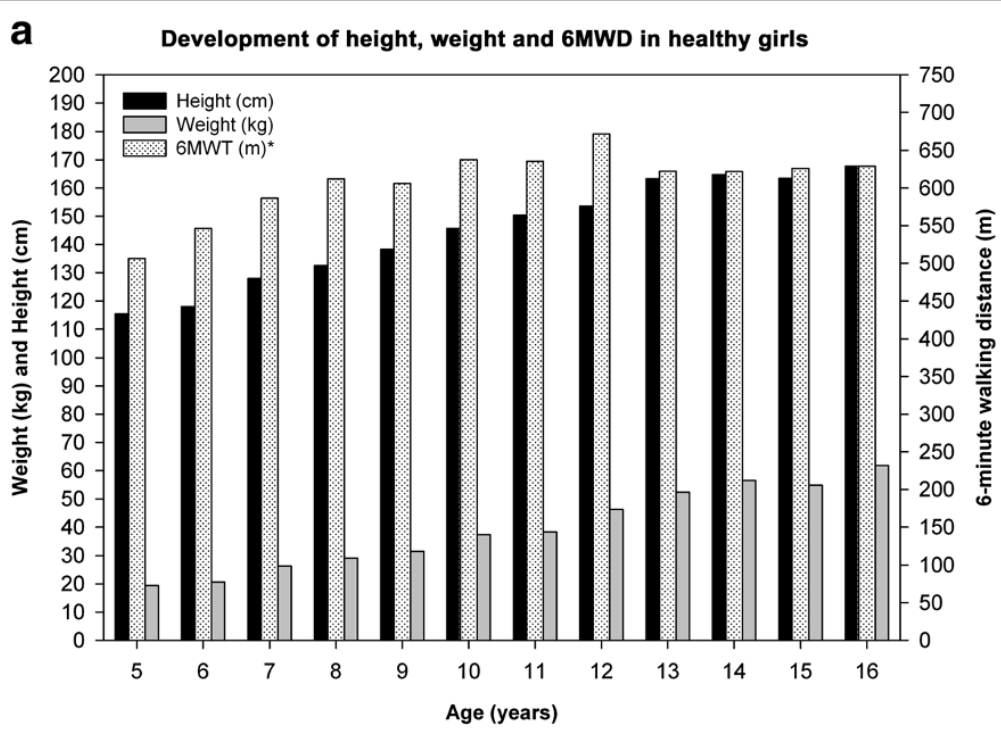

b

Development of height, weight and 6MWD in healthy boys

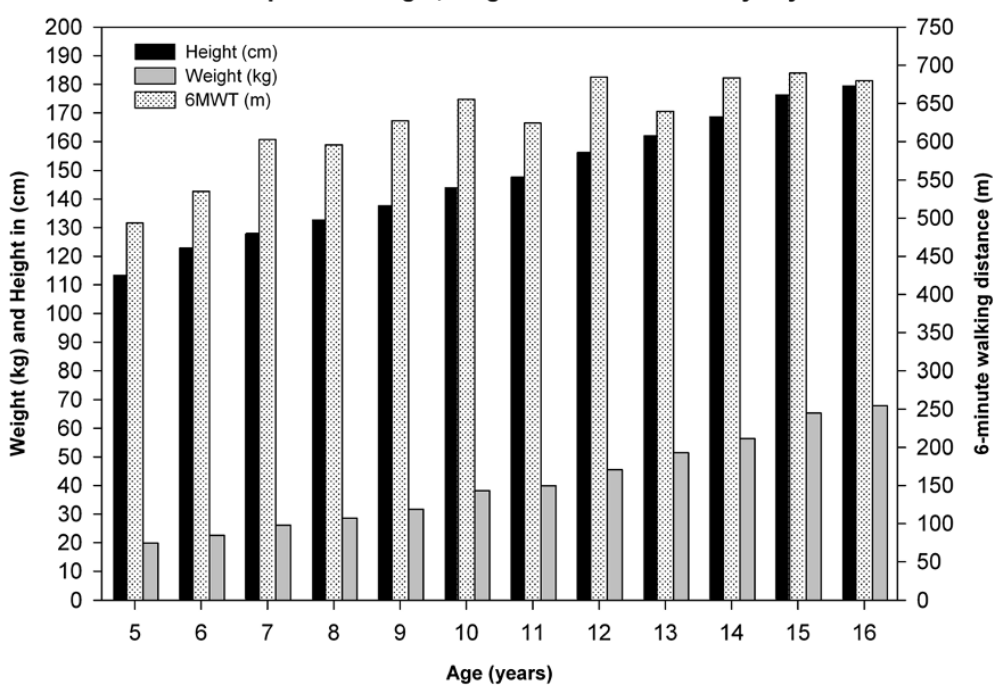

Figure 1 Shows the development of gender-related anthropometrics in healthy children between 5 to 16 years of age. (a). Association between 6-minute walking distance (6MWD), height, weight and age in healthy Caucasian girls and (b). Association between 6-minute walking distance (6MWD), height, weight and age in healthy Caucasian boys. 


\section{Results}

General

A total of 496 children and adolescents (252 girls) were included upon written informed consent. All participants were healthy according to the predefined questionnaire. Subjects' characteristics are shown in Table 1. All children completed the entire 6MWT according to the protocol and thus none of them had to be excluded from the study. In no case it was necessary to stop the test prematurely, and there were no unexpected events during the tests.

\section{Gender-related characteristics in 6 minute walk distance, body dimensions and vital signs}

Overall, the mean distance walked within six minutes was $618 \pm 79$ meters. Whereas weight and height steadily increased with age, the 6MWD mainly increased until puberty and then flattened (Figure $1 \mathrm{a}$ and b). 6MWD distances, vital signs by gender-specific yearly age groups are shown in Table 2 and Figure 2.

In females, the increase in 6MWD peaked just at the time of assumed puberty (around age 12) and then decreased back to a level already reached with about 9 years. In boys, the peak was similarly found around age 12 , however, with exception of a temporary drop with 13, they kept the peak 6MWD reached (Figure 2). Further analysis revealed that taking a cut-off point a year earlier or later would not have changed the main prediction.

We found a significant difference between boys and girls in the 6MWD $(626 \pm 65 \mathrm{~m}$ versus $608 \pm 55 \mathrm{~m})$ and the PAS (3 versus 2$)(\mathrm{p}<.001$ and .017 , respectively). We found no other overall gender-specific differences. Separate analysis for children $<12$ and $\geq 12$ years revealed significant difference in the 6MWD and PAS only for adolescents ( $\mathrm{p}=.000$ for both). Analysis by yearly age groups revealed significant gender-specific difference in the 6MWD for 14, 15 and 16 year old and PAS-

Table 2 Age stratified characteristics and Six-minute walk test

\begin{tabular}{|c|c|c|c|c|c|c|c|c|c|c|}
\hline \multirow[b]{2}{*}{ Sex } & \multirow[b]{2}{*}{$\begin{array}{c}\text { Age categroy } \\
\text { (year) }\end{array}$} & \multirow[b]{2}{*}{ n (\%) } & \multirow[b]{2}{*}{ Height (cm) } & \multirow[b]{2}{*}{ Weight (kg) } & \multirow[b]{2}{*}{$\begin{array}{c}\mathrm{BMI} \\
\left(\mathrm{kg} / \mathrm{m}^{2}\right)^{*}\end{array}$} & \multirow[b]{2}{*}{$\begin{array}{c}\text { 6MWT } \\
(\mathrm{m})^{*}\end{array}$} & \multicolumn{2}{|c|}{ Before 6MWT } & \multicolumn{2}{|c|}{ After 6MWT } \\
\hline & & & & & & & $\begin{array}{c}\text { MAP } \\
(\mathrm{mmHg})^{*}\end{array}$ & $\begin{array}{c}\text { HR } \\
(b p m)^{*}\end{array}$ & $\begin{array}{c}\mathrm{MAP}^{*} \\
(\mathrm{mmHg})\end{array}$ & $\begin{array}{c}\mathrm{HR}^{*} \\
(\mathrm{bpm})\end{array}$ \\
\hline \multirow{11}{*}{ Male } & 5 & $19(8)$ & $113 \pm 6$ & $20 \pm 3$ & $15.5 \pm 2.3$ & $494 \pm 60$ & $70 \pm 7$ & $104 \pm 19$ & $77 \pm 8$ & $132 \pm 20$ \\
\hline & 6 & $22(9)$ & $123 \pm 5$ & $23 \pm 3$ & $14.8 \pm 1.6$ & $535 \pm 73$ & $72 \pm 8$ & $100 \pm 15$ & $80 \pm 10$ & $122 \pm 30$ \\
\hline & 7 & $19(8)$ & $128 \pm 6$ & $26 \pm 4$ & $15.8 \pm 1.7$ & $603 \pm 51$ & $74 \pm 5$ & $96 \pm 15$ & $83 \pm 6$ & $131 \pm 21$ \\
\hline & 8 & $22(9)$ & $133 \pm 7$ & $29 \pm 4$ & $16.1 \pm 1.1$ & $596 \pm 59$ & $79 \pm 8$ & $96 \pm 17$ & $85 \pm 10$ & $129 \pm 21$ \\
\hline & 9 & $18(7)$ & $138 \pm 6$ & $32 \pm 4$ & $16.6 \pm 1.6$ & $627 \pm 70$ & $77 \pm 7$ & $94 \pm 12$ & $84 \pm 9$ & $138 \pm 19$ \\
\hline & 10 & $19(8)$ & $144 \pm 7$ & $38 \pm 8$ & $18.2 \pm 2.5$ & $655 \pm 53$ & $82 \pm 9$ & $97 \pm 14$ & $95 \pm 7$ & $141 \pm 25$ \\
\hline & 11 & $23(9)$ & $148 \pm 6$ & $40 \pm 10$ & $18.1 \pm 3.8$ & $624 \pm 87$ & $80 \pm 9$ & $94 \pm 12$ & $88 \pm 10$ & $139 \pm 20$ \\
\hline & 12 & $20(8)$ & $156 \pm 9$ & $46 \pm 10$ & $18.4 \pm 2.6$ & $685 \pm 74$ & $82 \pm 7$ & $93 \pm 9$ & $89 \pm 9$ & $145 \pm 30$ \\
\hline & 13 & $21(9)$ & $162 \pm 9$ & $51 \pm 10$ & $19.5 \pm 2.9$ & $639 \pm 49$ & $83 \pm 9$ & $96 \pm 15$ & $87 \pm 8$ & $129 \pm 18$ \\
\hline & 14 & $20(8)$ & $169 \pm 6$ & $56 \pm 10$ & $19.7 \pm 2.8$ & $684 \pm 81$ & $86 \pm 9$ & $98 \pm 20$ & $94 \pm 6$ & $138 \pm 25$ \\
\hline & 15 & $20(8)$ & $176 \pm 7$ & $65 \pm 13$ & $20.9 \pm 3.8$ & $690 \pm 71$ & $92 \pm 10$ & $103 \pm 24$ & $100 \pm 9$ & $141 \pm 24$ \\
\hline \multirow{13}{*}{ Female } & 16 & $21(9)$ & $180 \pm 9$ & $68 \pm 13$ & $20.9 \pm 3.2$ & $680 \pm 55$ & $93 \pm 10$ & $88 \pm 16$ & $100 \pm 10$ & $135 \pm 28$ \\
\hline & 5 & 19 (8) & $115 \pm 5$ & $19 \pm 3$ & $14.5 \pm 1.5$ & $506 \pm 39$ & $71 \pm 7$ & $95 \pm 17$ & $77 \pm 6$ & $129 \pm 17$ \\
\hline & 6 & $21(8)$ & $118 \pm 6$ & $21 \pm 4$ & $14.7 \pm 1.6$ & $546 \pm 51$ & $69 \pm 6$ & $94 \pm 21$ & $79 \pm 8$ & $137 \pm 17$ \\
\hline & 7 & $19(8)$ & $128 \pm 6$ & $26 \pm 5$ & $16 \pm 2.4$ & $586 \pm 59$ & $71 \pm 8$ & $99 \pm 14$ & $82 \pm 7$ & $132 \pm 20$ \\
\hline & 8 & $21(8)$ & $133 \pm 7$ & $29 \pm 6$ & $16.5 \pm 1.9$ & $612 \pm 40$ & $78 \pm 7$ & $96 \pm 17$ & $84 \pm 12$ & $130 \pm 17$ \\
\hline & 9 & $18(7)$ & $138 \pm 5$ & $32 \pm 4$ & $16.4 \pm 1.8$ & $606 \pm 52$ & $77 \pm 11$ & $96 \pm 19$ & $87 \pm 9$ & $139 \pm 18$ \\
\hline & 10 & $22(9)$ & $146 \pm 7$ & $37 \pm 8$ & $17.5 \pm 3.0$ & $638 \pm 63$ & $78 \pm 9$ & $98 \pm 14$ & $82 \pm 11$ & $140 \pm 22$ \\
\hline & 11 & $20(8)$ & $150 \pm 8$ & $38 \pm 10$ & $16.7 \pm 2.6$ & $636 \pm 54$ & $80 \pm 7$ & $91 \pm 17$ & $83 \pm 8$ & $148 \pm 19$ \\
\hline & 12 & $20(8)$ & $154 \pm 8$ & $46 \pm 9$ & $19.5 \pm 2.7$ & $672 \pm 55$ & $82 \pm 8$ & $94 \pm 12$ & $92 \pm 9$ & $153 \pm 21$ \\
\hline & 13 & $27(11)$ & $163 \pm 7$ & $52 \pm 10$ & $19.6 \pm 3.1$ & $622 \pm 76$ & $82 \pm 9$ & $96 \pm 14$ & $88 \pm 9$ & $135 \pm 25$ \\
\hline & 14 & $23(9)$ & $165 \pm 7$ & $56 \pm 8$ & $20.8 \pm 2.4$ & $622 \pm 64$ & $85 \pm 7$ & $90 \pm 18$ & $90 \pm 10$ & $132 \pm 24$ \\
\hline & 15 & $22(9)$ & $163 \pm 6$ & $55 \pm 10$ & $20.5 \pm 2.9$ & $626 \pm 49$ & $89 \pm 12$ & $97 \pm 19$ & $95 \pm 12$ & $139 \pm 20$ \\
\hline & 16 & $20(8)$ & $168 \pm 7$ & $62 \pm 9$ & $21.8 \pm 2.4$ & $629 \pm 52$ & $85 \pm 8$ & $88 \pm 14$ & $97 \pm 10$ & $134 \pm 17$ \\
\hline
\end{tabular}

Age stratified characteristics and 6-minute walking test in male and female participants. ${ }^{*}$ Values presented as mean $\pm S D . B M I\left(\mathrm{~kg} / \mathrm{m}^{2}\right)$, Body mass index, MAP mean arterial blood pressure $(\mathrm{mmHg}) ; H R$ Heart rate (beats/minute); $\mathrm{SpO}_{2}$ Transcutanous oxygen saturation (\%), 6MWT, 6-minute walk test. 


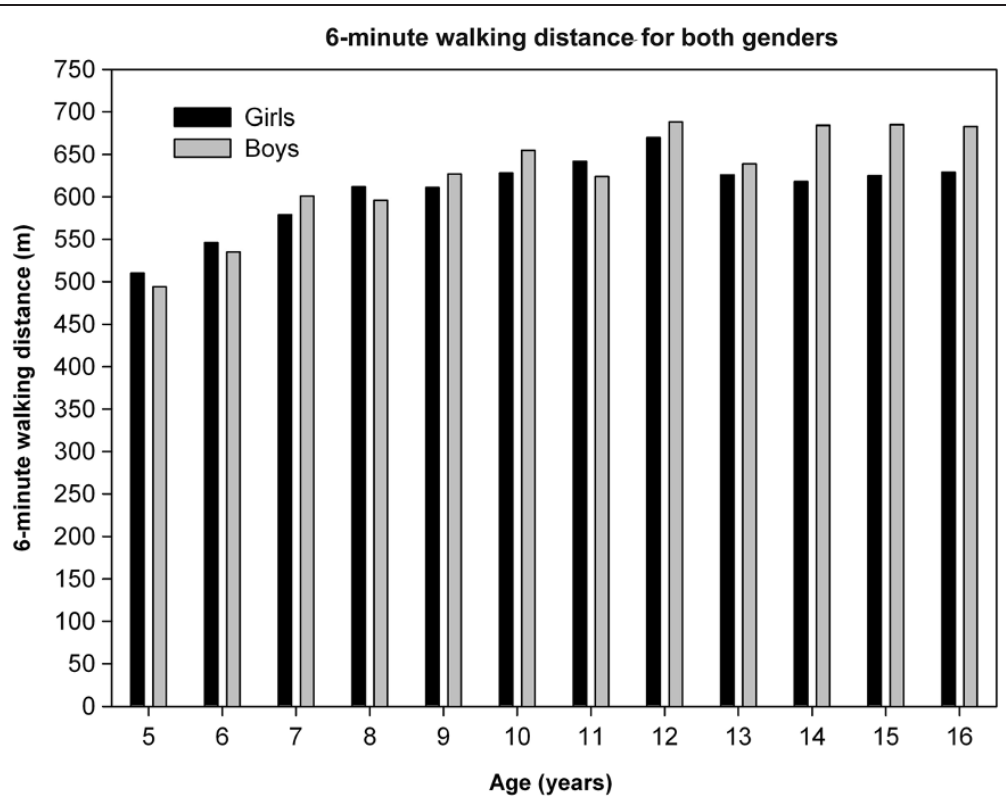

Figure 2 Association between 6-minute walking distance (6MWD) and age in healthy Caucasian girls and boys.

difference for 9, 12, 13, 14 and 15 years old (lower 6MWD and PAS in females).

The MAP increased with age, whereas the heart rate overall slightly decreased with increasing age groups (Figure $3 \mathrm{a}$ and $3 \mathrm{~b}$ ).

The MAP slightly increased with exercise, on average $7 \mathrm{mmHg}$, without any significant gender or age differences. The mean heart rate at the end of the 6MWT was $136 \pm 23 \mathrm{bpm}$. The HR considerably increased by a mean of $41 \pm 22 \mathrm{bpm}$ ( $43 \%$ change from resting heart rate) without major differences between age groups. We found a slightly higher exercise increase in HR in girls compared with boys (43 vs. $40 \mathrm{bpm}, \mathrm{p}=.025$ ). The $\mathrm{SpO}_{2}$ remained stable in both sex over all ages and after exercise.

\section{Correlations and equations to calculate normal 6MWD in healthy children \\ Total group}

We found a significant univariate correlation of age, height, weight, BMI, resting and peak exercise blood pressures, exercise HR and PAS with the 6MWD (all $\mathrm{p}<.0001$ ). Linear regression revealed the following formula to calculate overall age-adjusted 6MWD: 6MWD $=11.89 \times$ age $(y)+486.1$ $(\mathrm{p}=.000$, DW 2.045, see Table 3). Multiple, stepwise linear regression in a model including age, weight and height revealed that in this model age did no longer add information to mere weight and height. Normal values for the 6MWD could therefore be calculated from height and weight as follows (overall anthropometric formula): $6 \mathrm{MWD}=391.9 \times$ height $(\mathrm{m})-2.41 \times$ weight $(\mathrm{kg})+140.2$ $(\mathrm{p}=.000$, DW 2.032). The same regression models were then calculated separated by gender and sub-divided by an assumed puberty of 12 years in girls and 13 years in boys (Table 3).

\section{Equations by gender}

In girls, we found a significant univariate correlation of age, height, weight, BMI, resting and exercise blood pressure and HR with the 6MWD (all $\mathrm{p}=.000$ ), but not with PAS. Linear regression revealed significant age dependency of the 6MWD for girls $(\mathrm{p}=.000$, DW 2.187, Table 3). Addition of weight and height revealed that age did no longer add information. Thus, a 7 year old girl being $1.25 \mathrm{~m}$ tall and weighing $25 \mathrm{~kg}$ would have a predicted walk distance of $575 \mathrm{~m}$ by the gender-specific age-adjusted equation, $572 \mathrm{~m}$ by the gender-specific anthropometric equation, and $569 \mathrm{~m}$ by both, the age-adjusted and anthropometric overall equation.

In boys, we found a significant univariate correlation of age, height, weight, BMI, baseline and exercise BP, exercise HR and the PAS with the 6MWD (all $\mathrm{p}<.000$ ). The predicted 6MWD in boys could be calculated by age $(p=.000$, DW 1.709, Table 3). Addition of weight and height revealed that both significantly added to the equation $(\mathrm{p}=.001, .001$ and .017, respectively, DW 1.724, Table 3).

\section{Differential equations before versus after puberty in girls} and boys

In girls $<12$ years, linear regression revealed that age significantly predicted the 6MWD $(\mathrm{p}=.000$, DW 1.901, Table 3). Multiple stepwise linear regressions by adding 


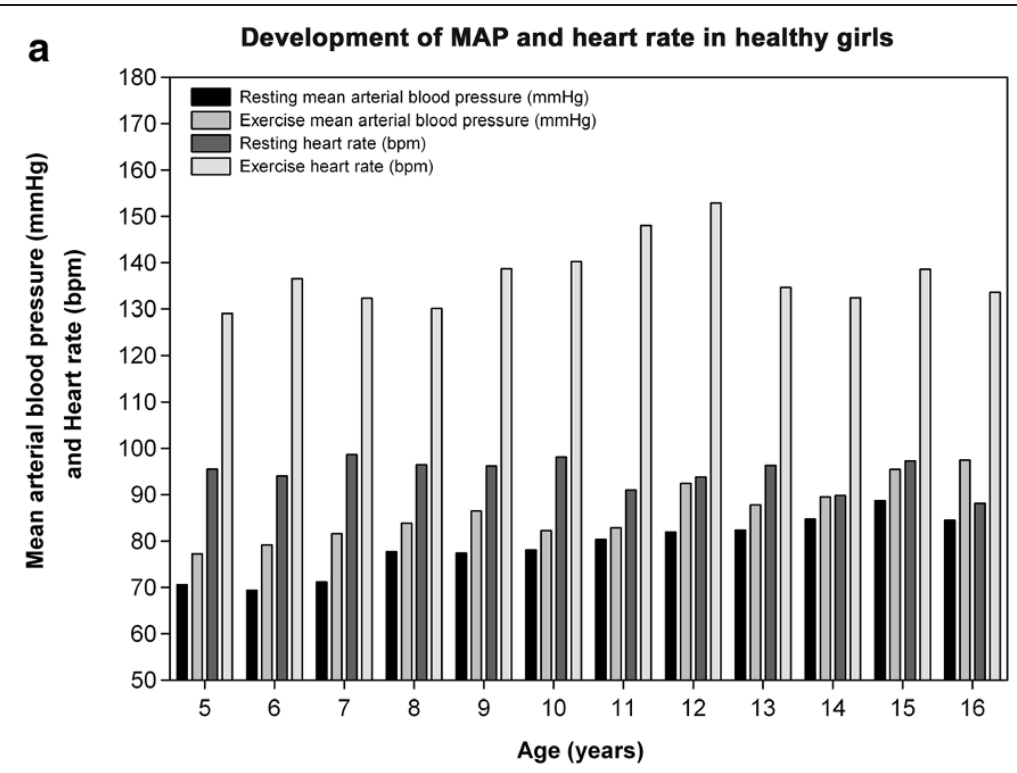

b

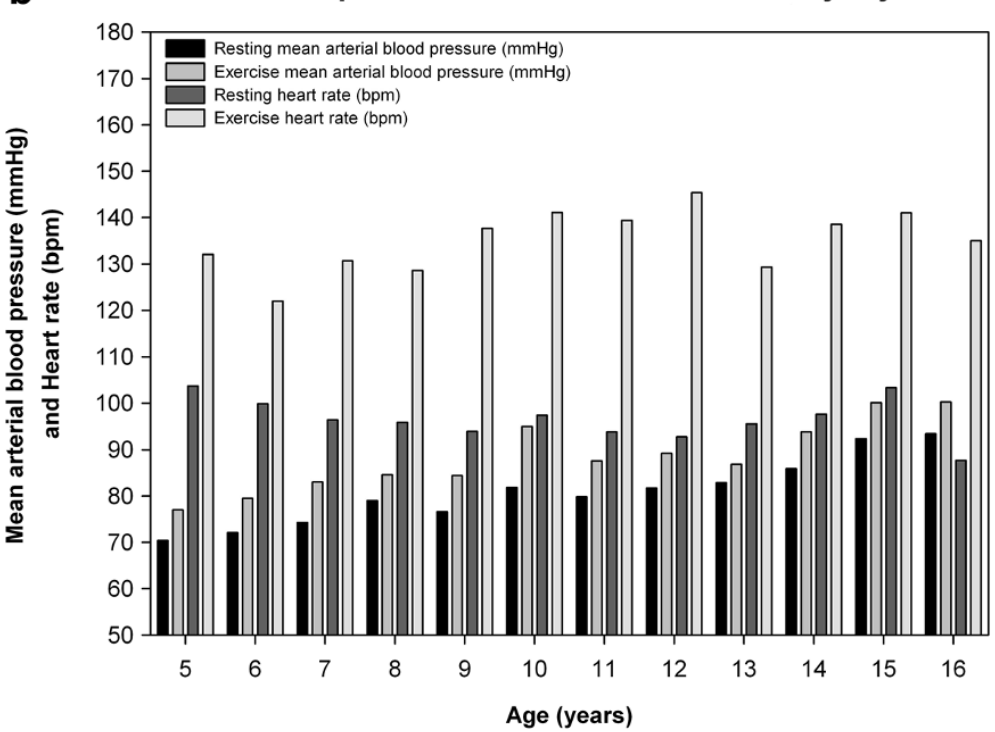

Figure 3 Shows the development of gender-related hemodynamics in healthy children between 5 to 16 years of age. (a). Association between mean arterial blood pressure (MAP) and heart rate during rest and exercise in different age groups of healthy Caucasian girls. (b). Association between mean arterial blood pressure (MAP) and heart rate during rest and exercise in different age groups of healthy Caucasian boys.

weight and height reveal that only height did significantly count below the age of 12 years in girls $(\mathrm{p}=.000$, DW 1.928). Thus, the predicted 6MWD for a 7-year-old girl being $1.25 \mathrm{~m}$ tall would herewith be $566 \mathrm{~m}$.

In female adolescents' $\geq 12$ years, age was still a significant predictor of the $6 \mathrm{MWD}$, however, the significance is lower ( $\mathrm{p}=.036$, DW 1.901). Addition of height and weight revealed that only weight remained significant $(\mathrm{p}=.001, \mathrm{DW} 1.870)$.

A 14-year-old girl being $1.65 \mathrm{~m}$ tall and weighting 56 $\mathrm{kg}$ would have a predicted walk distance of $630 \mathrm{~m}$ (to compare: overall-equation of girls $634 \mathrm{~m}$ and height and weight adjusted $639 \mathrm{~m}$ ).

In boys $<13$ years, age significantly predicted the 6MWD ( $\mathrm{p}=.000$, DW 1.539) and neither height nor weight added to age to predict the 6MWD in preteenage boys. In adolescent boys $\geq 13$ years, age remained the only significant predictor of the $6 \mathrm{MWD}$, weight and height did not add $(\mathrm{p}=.031$, DW 1.789, Table 3).

A 14-year-old boy has a predicted walk distance of $660 \mathrm{~m}$ (to compare: overall equation for boys $671 \mathrm{~m}$ ). 
Table 3 Equations to predict the 6 minute walk distance in children and adolescents

\begin{tabular}{|c|c|c|c|c|c|c|}
\hline Model & Age-adjusted & & + height-, weight-adjusted & & + vitals and physical activity score (PAS) & \\
\hline Population & (age in years $(y))$ & $\mathrm{p}$ & $\begin{array}{l}\text { (age in } \mathrm{y} \text {, height in } \mathrm{m} \text {, } \\
\text { weight in } \mathrm{kg} \text { ) }\end{array}$ & $\mathrm{p}$ & (heart rate (HR) in bpm, PAS 1-4) & p \\
\hline General & $11.89 * y+486.1$ & $.000, .000$ & $391.9^{*} \mathrm{~m}-2.41^{*} \mathrm{~kg}+140.2$ & $.000, .000, .000$ & $192.69^{*} m+1.27^{*}$ exHR +161.55 & $.000, .000, .000$ \\
\hline Males & $15.36 * y+456.92$ & $.000, .000$ & $\begin{array}{l}13.40^{*} y-2.16^{*} \mathrm{~kg}+ \\
196.53^{*} \mathrm{~m}+276.92\end{array}$ & $.001, .001, .017, .000$ & $\begin{array}{c}14.38^{*} \mathrm{y}+1.21^{*} \mathrm{exHR}-2.12^{*} \mathrm{~kg}+ \\
166.66^{*} \mathrm{~m}+146.56\end{array}$ & $.000, .000, .001, .037$ \\
\hline$<13$ y & $24.18^{*} y+385.18$ & $.000, .000$ & As age-adjusted & & $28.62^{*} y+1.26^{*}$ exHR $-2.034^{*} \mathrm{~kg}+239.29$ & $.000, .000, .014, .000$ \\
\hline$\geq 13 \mathrm{y}$ & $13.08 * y+476.69$ & $.031, .000$ & As age-adjusted & & $1.01^{*} \mathrm{exHR}+13.3^{*} y+338.25$ & $.001, .022, .000$ \\
\hline Females & $8.623^{*} y+513.7$ & $.000, .000$ & $372.3^{*} \mathrm{~m}-2.635^{*} \mathrm{~kg}+172.05$ & $.000, .000, .001$ & $152.58^{*} m+1.38^{*}$ exHR +197.97 & $.000, .000, .000$ \\
\hline$<12 y$ & $20.83^{*} y+413.94$ & $.000, .000$ & $330.07^{*} m+153.3$ & $.000, .000$ & $279.5^{*} \mathrm{~m}+.87^{*} \mathrm{exHR}+102.45$ & $.000, .000, .024$ \\
\hline$\geq 12 y$ & $-8.66^{*} y+757.42$ & $.000, .036$ & $-1.867 * \mathrm{~kg}+734.29$ & $.001, .000$ & $\begin{array}{c}1.79^{*} \text { exHR }-1.28^{*} \text { restHR }-2.55^{*} \mathrm{~kg}+ \\
203.3^{*} \mathrm{~m}+7.83^{*} \mathrm{PAS}+298.6\end{array}$ & $\begin{array}{l}.000, .000, .000, .023 \\
.032, .030\end{array}$ \\
\hline
\end{tabular}

${ }^{*}$ multiplied by, $Y$ years, $m$ meters of body height, $\mathrm{kg}$ kilogram body weight, HR heart rate, restHR heart rate before the 6MWD, exHR HR after the 6MWD. PAS physical activity score as measure of self-reported activity going from 0 ( 0 hours weekly of physical activity beside school sports to $>4$ hours of physical activity) to $4 \mathrm{P}$ values are given for all parameters added in the equation model in order that the reader can see the impact of each measure to the equation.

\section{Impact of vital signs and physical activity scores to predicted 6MWD}

Univariate correlation revealed that beside age, height and weight, also exercise HR, MAP at rest and exercise and PAS significantly correlated with the 6MWD. However, gender-separated analysis revealed that PAS correlated with the 6MWD only in boys. Inclusion of vitals at rest and exercise and the PAS in the stepwise regression model in addition to age, weight and height revealed that only exercise HR added information to age and anthropometrics in gender-specific analysis (Table 3).

If this extended model was analysed in gender-specific before puberty, we found that in girls, the exercise HR and height were significant predictors of the 6MWD, whereas in boys, exercise HR, age, and weight were significant predictors (Table 3 ).

In adolescents, this extended model revealed that in girls the rest and exercise $\mathrm{HR}$, weight, height and PAS all significantly added to the prediction equation, whereas in adolescent males only exercise HR and age were significant predictors of the 6MWD.

\section{Discussion}

Our study shows that the 6MWD in healthy children and adolescents is feasible. The 6MWD was clearly related to gender and age. On the basis of our study we provide gender-specific, age-adjusted reference equations and percentile curves (Figure $4 \mathrm{a}$ and $4 \mathrm{~b}$ ) for the $6 \mathrm{MWT}$ in healthy children and adolescents living in Switzerland.

Multivariate stepwise models revealed that weight and height may be taken into account; however, their value added is mostly limited and depends on age-subgroup analysed. Beside age and anthropometrics, the HR achieved at peak exercise added to predict the 6MWD, whereas questionnaire assessed physical activity only weakly contributed in post-pubertal girls.
The 6MWT has become a standard in clinical practise and research as a simple tool to assess exercise performance, function and response to treatment in adults with cardiorespiratory disorders [1]. In analogy to the adult population, the 6MWT has become increasingly important in children with cardiorespiratory disorders and it has been shown to be reproducible, reliable and valid [14]. In adults it is still controversial if the absolute 6MWD is best to assess performance and outcome or if expressing the $6 \mathrm{MWD}$ in per cent predicted would be better [9]. Reference equations for the 6MWD in adults are available since over a decade [7]. However, they failed to date to show a clear advantage over absolute values. Current guidelines state that the 6MWD is influenced by age, sex, weight, height and motivation, but despite this, absolute thresholds around $<330-380$ $\mathrm{m}$ are mostly mentioned to be predictors of a poorer prognosis $[1,15,16]$. Despite this lack of proven clinical validity to express the $6 \mathrm{MWD}$ in \% predicted in adults, it is obvious that in children and adolescents the influence of age and/or anthropometrics by far outreaches their potential influence on 6MWD compared to adults. Therefore, reference equations for the 6MWD in children and adolescents are of importance for clinicians and researchers treating and assessing children with cardiorespiratory disorders. Li et al. performed 6MWT in healthy children aged 7-16 years in Hong-Kong and found a strong correlation with height [6]. However, Asian children are known to have different anthropometrics compared to Caucasian counterparts. In our Swiss and purely Caucasian collective, we found some influence of height, mainly in prepubertal girls, and weight, mainly in adolescent women. However, age alone was a significant predictor of the distance walked overall and in different subgroups. Lammers et al. performed $6 \mathrm{MWT}$ in children aged 4-11 years in the UK and 


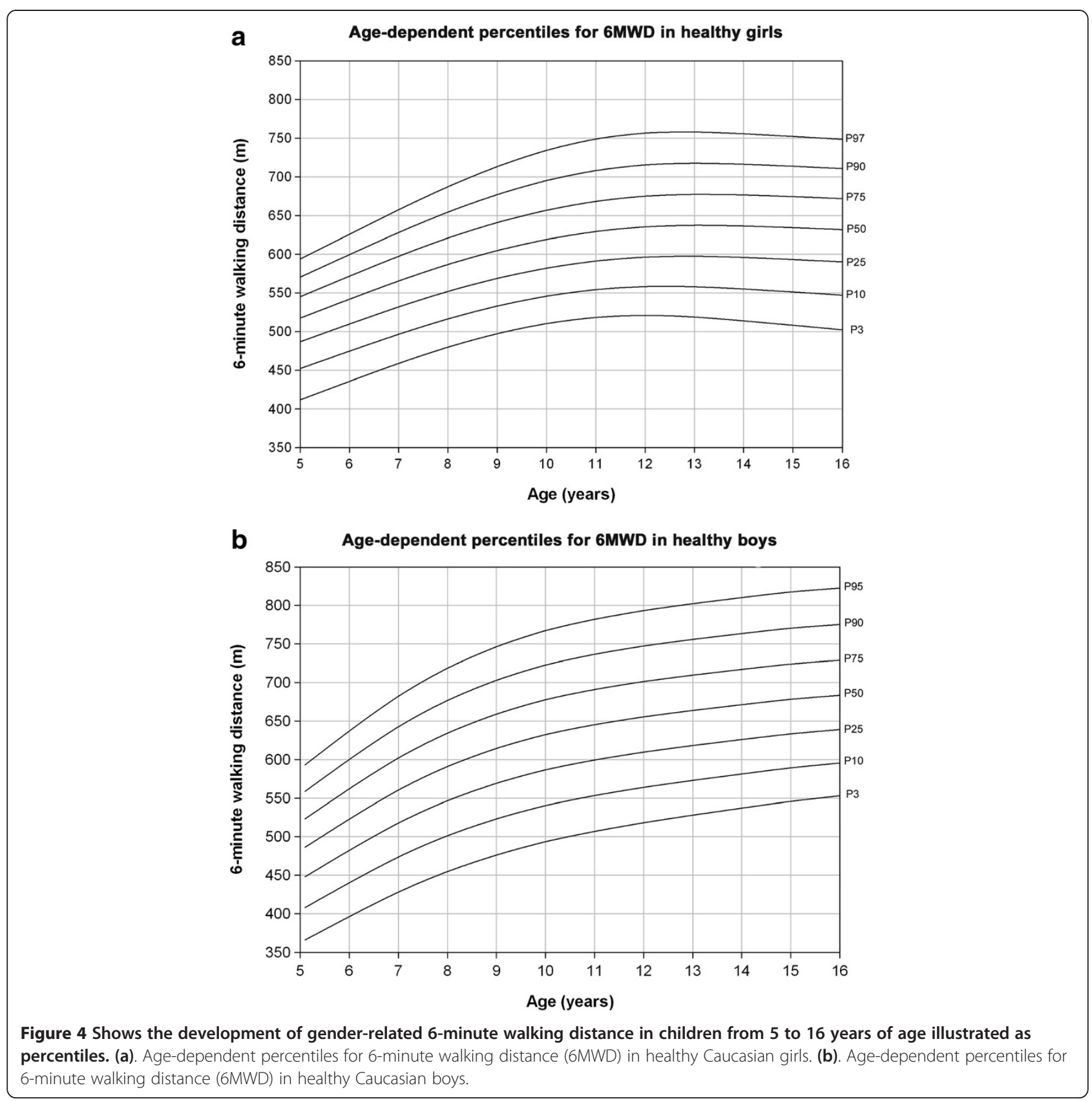

found that in this collective with $83 \%$ Caucasians age alone accounted for $41 \%$ of the variation in $6 \mathrm{MWD}$, if weight and height were added, $44 \%$ could be explained [11]. In our collective, age alone was a significant predictor of the 6MWD overall, gender-specific overall and separately addressed for prepubertal and post pubertal children and adolescents. If height and weight were coanalysed with age in a multivariate stepwise model we found that age alone performed similarly well in genderspecific and overall analysis (Table 3). Reference equations including weight and height might be taken into account for children with anthropometrics at the margins of the normal distribution, e.g. extremely thin, obese, small or large. Therefore we were able to plot age-adjusted normal percentile curves for the 6MWD for children and adolescents and can recommend their use in everyday practice (Figure $4 \mathrm{a}$ and $4 \mathrm{~b}$ ). These curves may help to visualize a sick child's performance in relation to healthy coevals and to observe the performance over time, as it is known for many percentile 
curves in paediatrics, such as weight and height. In addition, we can provide simple age-adjusted, genderspecific reference equations to assess the \% predicted of the 6MWD in girls and boys (Table 3).

In order get insight into the performance of children compared to adolescents we did subgroup analysis by separating girls at an age cut-off of 12 and boys with 13 years. We choose these cut-off points according to assumed midpuberty at around this age. However, further analysis revealed that taking a cut-off point a year earlier or later would not have changed the main results. In females we found that height significantly predicted the
6MWD in prepubertal girls, whereas in adolescents, weight had to be taken into account. We found that anthropometrics did not add to calculate reference values of the 6MWD in boys and adolescent males.

A further interest of this study was to address the impact of $\mathrm{HR}, \mathrm{BP}, \mathrm{SpO}_{2}$ and reported physical activity assessed by a score on the $6 \mathrm{MWD}$. According to normal children's development, resting BP slightly increased and HR tended to decrease with age. The BP slightly increased with exercise (mean increase $7 \mathrm{mmHg}$ ), the exercise HR increased overall by a mean of $40 \%$. As others $[11,17]$, we found a slightly higher exercise increase in

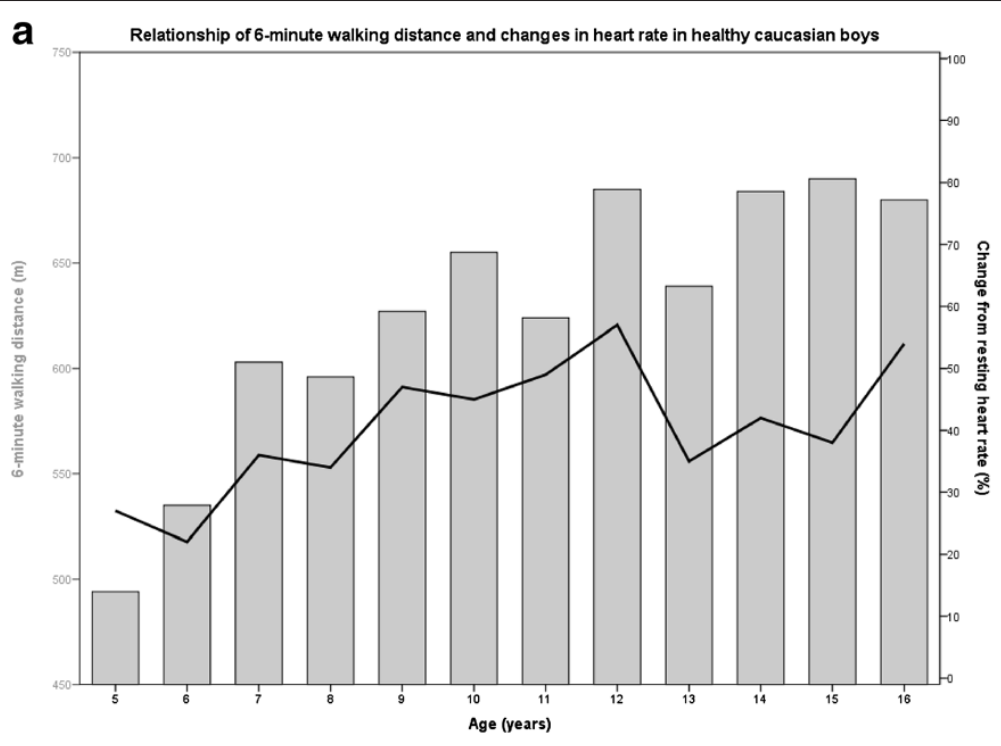

b

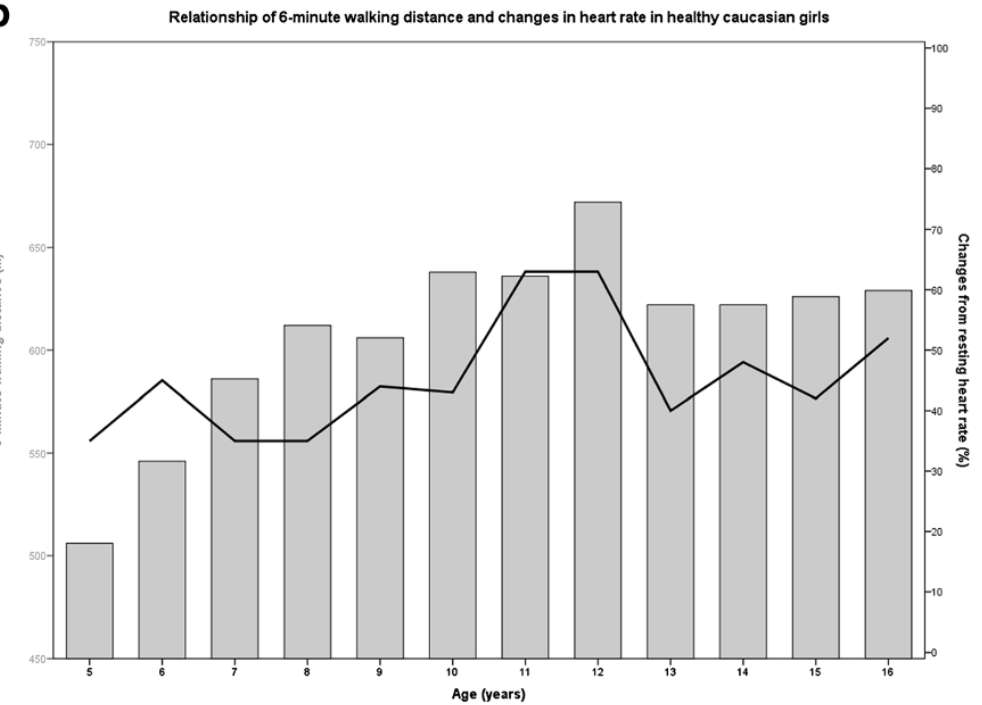

Figure 5 Shows the 6-minute walking distance walked by children from 5 to 16 years of age and the related physical effort to achieve this distance. (a). Relationship of 6-minute walking distance (6MWD) and changes in heart rate in healthy Caucasian boys. (b). Relationship of 6-minute walking distance (6MWD) and changes in heart rate in healthy Caucasian girls. 
HR in girls compared with boys. Interestingly, we found that the HR achieved at peak 6MWD (exercise HR) significantly added to gender and age to calculate normal $6 \mathrm{MWD}$, even if equations were calculated separately for the subgroups before and after puberty. The degree of HR increase during exercise most probably reflects a higher effort (Figure $5 \mathrm{a}$ and $5 \mathrm{~b}$ ). These findings are novel and indicate that the effort taken expressed by exercise HR significantly influences the 6MWD.

In order to get information about physical activity and fitness of the healthy children investigated, we asked them or their legal representatives about participation in sport and other physical activity and scored this with numbers (from 0 to 4 , no up to 4 additional weekly activity hours). However, this PAS added significant information to predict the 6MWD only in adolescent girls. Potentially, the questionnaire to assess this PAS did not really reflect physical activity in everyday life. It may well be that some children were very active outdoors in gardens and playground without achieving a high PAS as they did not count outdoor playing to Sports activity. The better performance of this score in adolescents may point towards this direction.

Our work has the following limitations: In our study, the 6MWD was measured only once in every child. So we cannot provide information on the test - retest reliability. We did not include an instrument to measure specific motivation in our study. As we included several children and adolescents of each age group, we believe that the inter-individual differences in motivation would somehow equilibrate around the average. Although we tried to include consecutive children living in different areas without any selection criteria, we cannot exclude a selection bias with potentially more motivated subjects being investigated by us. As we did only the 6MWD test as described in the methods, we do not know the relationship of our test to other submaximal exercise test such as cadence-based estimates or a method including stride length $[10,18]$. A head-to-head comparison of different tests would be interesting, but also logistically demanding as performing more than one test would potentially be biased by the time sequence. We did also not simultaneously assess other parameters of physiology, such as lung function tests. Peripheral oxygen saturation was normal and remained normal during the test in all healthy children as expected. Our normative values and reference equations are only usable for the age group we investigated. Thus, they will not apply for very young children and toddlers, in which a $6 \mathrm{MWD}$ test might as well be difficult to perform. Despite these limitation, in our experience, the present form of the 6MWD is easy performable and utile as comparative measures in the management and follow-up of children and adolescents with cardiorespiratory diseases.

\section{Conclusions}

In summary, in this study we can provide sound reference equations and age-adjusted percentile curve to assess the predicted 6MWD derived from a well-powered and gender-adjusted Swiss cohort. We could show that overall, age was the most important predictor, especially for prepubertal children and boys, anthropometrics significantly add mainly in girls. Exercise HR significantly adds to predict the 6MWD and can be included to calculate effort-adjusted walk distances.

\section{Abbreviations \\ 6MWD: 6-minute walking distance; 6MWT: 6-minute walk test; BMI: Body mass index; BP: Blood pressure; DW: Durbin-Watson test; HR: Heart Rate; MAP: Mean arterial pressure; PAS: Physical activity score; SD: Standard Deviation; $\mathrm{SpO}_{2}$ : Peripheral oxygen saturation.}

\section{Competing interests}

The authors declare that they have no competing interests.

\section{Authors' contributions}

All authors had full access to the data and read and approved the final manuscript. SU developed the concept of this study, was involved in analysing the data, carried out the statistical analysis and participated in the interpretation, the critical revision of the study and final approval of the manuscript. FFH was involved in acquisition of data, analysis and interpretation of data, drafting the manuscript and revising it critically for important intellectual content and provided final approval of the version to be published. UT was involved in acquiring the study subjects, taking care for the children during the study period, supervising the data acquisition and performing the tests. MF and SK made substantial contributions to the current study and publication, participating in the study process, analysis of data, development and revisions of the manuscript and has approved the final manuscript draft. RS was involved in the interpretation of data and critical reading and revision of the draft manuscript. MAF was involved in analysing the data, carried out the statistical analysis and participated in the interpretation, the critical revision of the study and final approval of the manuscript. All authors read and approved the final manuscript.

\section{Acknowledgements}

We thank Sara Mettler for her excellent nursing assistance. We also thank Dr. med. S. Stronski, Zürich, all authorities of the participating schools and all participant.

\section{Funding}

This work was supported by the Swiss National Science Foundation (grant \# 32003B-130844).

\section{Author details}

'Department of Heart, Vessel, Thorax, University Hospital of Zurich,

Switzerland and Centre of Integrative Human Physiology, Zurich, Switzerland. ${ }^{2}$ Research Fellow Pulmonary Hypertension Unit, Department of Heart, Vessel, Thorax, University Hospital of Zurich, Zurich, Switzerland. ${ }^{3}$ Department of Internal Medicine and Oncology, Pulmonary hypertension unit, University Hospital of Zurich, Zurich, Switzerland. ${ }^{4}$ Department of Internal Medicine, City Hospital Waid, Zurich, Switzerland. ${ }^{5}$ Research Fellow Pulmonary Hypertension, Unit Department of Heart, Vessel, Thorax, University Hospital of Zurich, Zurich, Switzerland. ${ }^{6}$ Department of Internal Medicine and Oncology, University Hospital of Zurich, Zurich, Switzerland. ${ }^{7}$ Paediatric Clinic, University Children's Hospital Zurich, Zurich, Switzerland. ${ }^{8}$ Respiratory Clinic, University Hospital of Zurich, Rämistrasse 100, 8091 Zürich, Switzerland.

Received: 18 January 2013 Accepted: 17 July 2013

Published: 5 August 2013

\section{References}

1. ATS statement: guidelines for the six-minute walk test. Am J Respir Crit Care Med 2002, 166:111-117. 
2. Enright PL: The six-minute walk test. Respir Care 2003, 48:783-785.

3. Rasekaba T, Lee AL, Naughton MT, Williams TJ, Holland AE: The six-minute walk test: a useful metric for the cardiopulmonary patient. Intern Med J 2009, 39:495-501.

4. Brown CD, Wise RA: Field Tests of Exercise in COPD: The Six-Minute Walk Test and the Shuttle Walk Test. COPD: Journal of Chronic Obstructive Pulmonary Disease 2007, 4:217-223.

5. Klepper SE, Muir N: Reference values on the 6-minute walk test for children living in the United States. Pediatr Phys Ther 2011, 23:32-40

6. Li AM, Yin J, Au JT, So HK, Tsang T, Wong E, Fok TF, Ng PC: Standard reference for the six-minute-walk test in healthy children aged 7 to 16 years. Am J Respir Crit Care Med 2007, 176:174-180

7. Enright $\mathrm{PL}$, Sherrill DL: Reference equations for the six-minute walk in healthy adults. Am J Respir Crit Care Med 1998, 158:1384-1387.

8. Chetta A, Zanini A, Pisi G, Aiello M, Tzani P, Neri M, Olivieri D: Reference values for the 6-min walk test in healthy subjects $20-50$ years old. Respir Med 2006, 100:1573-1578.

9. Casanova C, Celli BR, Barria P, Casas A, Cote C, de Torres JP, Jardim J, Lopez MV, Marin JM, Montes de Oca M, et al: The 6-min walk distance in healthy subjects: reference standards from seven countries. Eur Respir J 2011, 37:150-156.

10. Geiger R, Strasak A, Treml B, Gasser K, Kleinsasser A, Fischer V, Geiger H, Loeckinger A, Stein J: Six-minute walk test in children and adolescents. J Pediatr 2007, 150:395-399. 399 e391-392.

11. Lammers AE, Hislop AA, Flynn Y, Haworth SG: The 6-minute walk test: normal values for children of 4-11 years of age. Arch Dis Child 2008, 93:464-468

12. Nixon PA, Joswiak ML, Fricker FJ: A six-minute walk test for assessing exercise tolerance in severely ill children. J Pediatr 1996, 129:362-366.

13. Coats AJS, Shewan LG: Statement on authorship and publishing ethics in the international journal of cardiology. Int J Cardiol 2011, 153:239-240.

14. Li AM, Yin J, Yu CC, Tsang T, So HK, Wong E, Chan D, Hon EK, Sung R: The six-minute walk test in healthy children: reliability and validity. Eur Respir J 2005, 25:1057-1060.

15. Miyamoto S, Nagaya N, Satoh T, Kyotani S, Sakamaki F, Fujita M, Nakanishi N, Miyatake K: Clinical correlates and prognostic significance of sixminute walk test in patients with primary pulmonary hypertension. Comparison with cardiopulmonary exercise testing. Am J Respir Crit Care Med 2000, 161:487-492.

16. Sitbon $O$, Humbert M, Nunes $H$, Parent F, Garcia G, Herve P, Rainisio M, Simonneau G: Long-term intravenous epoprostenol infusion in primary pulmonary hypertension: prognostic factors and survival. J Am Coll Cardiol 2002, 40:780-788.

17. Ben Saad H, Prefaut C, Missaoui R, Mohamed IH, Tabka Z, Hayot M: Reference equation for 6-min walk distance in healthy North African children 6-16 years old. Pediatr Pulmonol 2009, 44:316-324.

18. Priesnitz CV, Rodrigues GH, Stumpf Cda S, Viapiana G, Cabral CP, Stein RT, Marostica PJ, Donadio MV: Reference values for the 6-min walk test in healthy children aged 6-12 years. Pediatr Pulmonol 2009, 44:1174-1179.

doi:10.1186/1471-2466-13-49

Cite this article as: Ulrich et al:: Reference values for the 6-minute walk test in healthy children and adolescents in Switzerland. BMC Pulmonary Medicine 2013 13:49.

\section{Submit your next manuscript to BioMed Central and take full advantage of:}

- Convenient online submission

- Thorough peer review

- No space constraints or color figure charges

- Immediate publication on acceptance

- Inclusion in PubMed, CAS, Scopus and Google Scholar

- Research which is freely available for redistribution

Submit your manuscript at www.biomedcentral.com/submit
Ciomed Central 